\title{
EDITORIAL
}

\section{International comparison of the work-related stressors experienced by psychiatrists}

\author{
M. Henderson and M. Abbas
}

Leeds and York Partnership NHS Foundation Trust, UK. Email: max henderson@nhs.net

Received 17 Dec 2018 Accepted 2 Jan 2019

doi:10.1192/bji.2019.1

(c) The Authors 2019. This is an Open Access article, distributed under the terms of the Creative Commons Attribution-

NonCommercial-NoDerivatives Commons Attibutioncommons org/licenses/by-nc-nd/4.0/), which permits non-commercial re-use, distribution, and reproduction in any medium, provided the original work is unaltered and is gropery ited. The written is merPress must be obtaned forsity Press must be obtained for com mercial re-use or in order to create a derivative work.
The mental health of psychiatrists is a live topic all over the world; both the Royal College of Psychiatrists (Royal College of Psychiatrists, 2018) and the World Psychiatric Association (WPA, 2017) have published position statements on the subject. This edition of BJPsych International includes four papers focusing on the challenges of psychiatric practice in different countries, each with a different economy, healthcare system and culture. It is heartening that each paints a broadly hopeful picture, notwithstanding the difficulties identified. Yet it would be shortsighted for policy makers, psychiatrists, their colleagues or their patients to conclude that all is well and there is nothing more to do.

In October, the chief executive of the English National Health Service, Simon Stevens, announced that funding would be made available for a national scheme to support the mental health of all doctors in England. This builds on the success of the Practitioner Health Programme, first established in London but since extended to all general practitioners in England (Practitioner Health Programme, 2018). Nearly 20 years after the death by suicide of Daksha Emson (North East London Strategic Health Authority, 2003), a trainee psychiatrist, the mental health of doctors has reached the top of the priority list, in England at least.

Raghuraman's paper on psychiatry in India (Raghuraman et al, 2008), Taylor-East's view on psychiatry in Malta (Taylor-East, 2018) and Abdul-Al's paper offering a perspective on psychiatry in the Arab world (Abdul-Al, 2018) all discuss stigma, drawing our attention to the stigma attached to being a psychiatrist. The experience of being steered away from a career in psychiatry either at medical school or as a junior doctor is commonplace, and happened to both the authors of this editorial. Unfavourable misconceptions and attitudes that originate within the medical community contribute to the recruitment crisis in psychiatry. The challenges of recruiting into psychiatric services is highlighted by Abdul-Al and, although new training programmes are being established, stigma within healthcare, general populations and political settings remains a barrier to the uptake of these places. Taylor-East talks about membership of the Royal College of Psychiatrists providing a feeling of being part of a larger community, yet psychiatry is too often seen as something 'other' and thus for the psychiatrist there is a loss of belonging to the wider medical profession. The college's Ban the Bash campaign was aimed at tackling this head on. Sadly, there is also reference to the distress of recent suicides; there is something poignant about the suicide of a mental health professional whose work involves reducing suicide in others. The effects on colleagues and patients as well as friends and families can be far-reaching and long-lasting.

One popular myth about medicine in general, and psychiatry in particular, is that it is the clinical work that upsets us and makes us ill. In psychiatry we take detailed histories and learn intimate, often traumatic and distressing, accounts of patients' experiences. Isn't this the major risk factor? Harvey et al in their review for the UK Department of Health in 2009 suggest not (Harvey et al, 2009). The conclusion of that review was that the working environment, largely the psychosocial work environment and how doctors are managed, posed the greatest risk to mental health. Support for Harvey's position is found across all four papers. Taylor-East describes improvements in morale and pride resulting from the development of a local psychiatry training scheme which retained psychiatric trainees on the island, assisting the development of working relationships. She emphasises the importance of the interface with primary care and with those in the general hospital, a point also picked up by Abdul-Al. Raghuraman highlights a range of management structures put in place specifically to support staff, including supervision, mentorship, frequent feedback and the means to raise concerns about harassment. Christodoulou's description of psychiatry in the context of the wider social and economic difficulties in Greece makes similar points, just on a bigger scale (Christodoulou and Kollias, 2018). The difficulties of working alongside a less well-developed primary care service contrasts sharply with that existing in Malta. The observation that mental health services at times compensate for underpressure social care systems will be recognised by psychiatrists in many settings.

What can be done to optimise the mental health and quality of life of psychiatrists across the world? One important aspect to address is the clarity and precision of our language. A plethora of new terms are now in common usage 'stress', 'burnout' and 'well-being'. None is a 
psychiatric term and each has a range of definitions in different settings. There is a risk of them being used interchangeably with betterdefined psychiatric language, or used in a way that suggests there is a continuum with more 'severe' psychiatric states. Scant evidence exists that interventions in the former somehow 'trickle down' and prevent the latter (Hotopf et al, 2015). There is more than enough mental illness in psychiatrists and other doctors, and this should be the focus for intervention now.

However, this does not mean simply more healthcare. Psychiatrists do of course need access to their own healthcare, and, where they can be provided, services like the Practitioner Health Programme can transform lives. Medical schools can train doctors to care for their own health too. As Raghuraman's paper shows, psychiatrists are very much better at spotting pathology in others than in themselves. And psychiatric training is no immunisation against mental illness. But it is in the local and wider environment that sustainable solutions should be sought. Christodoulou refers to 'preventive psychiatry', which sounds a lot like public mental health, with its emphasis on non-health risks and interventions, placing both mental illness and psychiatry itself in a broader context. This is a rapidly developing field with a burgeoning evidence base (Bhugra et al, 2018). Raghuraman makes reference to 'whole system healthy workplaces', an approach for which reasonable evidence exists already.

There is no health without mental health, and both mental health and psychiatric services cannot and should not be divorced from the healthcare settings, the cultures, the communities and the countries they aim to serve. There is no zerosum game. Our patients need us to be as healthy as possible to care for them. Improving the mental health of psychiatrists requires all of us, in whatever setting we work, to help generate healthy supportive workplaces, in cohesive communities, collaborating with colleagues across primary and secondary care, in countries working towards minimising health inequalities. In essence, precisely what we would wish for our patients.

\section{References}

Abdul-Al R. (2019) Sources of stress in the practice of psychiatry: perspective from the Arab world. Br J Psychiatry Int, 16(3).

Bhugra D, Bhui K, Wong S, et al (eds) (2018) Oxford Textbook of Public Mental Health. Oxford University Press.

Christodoulou NG, Kollias K. (2018) Current challenges for psychiatry in Greece. Br J Psychiatry Int, 16(3).

Harvey S, Laird B, Henderson M, et al (2009) The Mental Health of Healthcare Professionals. Department of Health.

Hotopf M, Mehta N, Henderson M, et al (2015) Wellbeing interventions: no evidence they prevent mental illness. Lancet, 386 852-853.

North East London Strategic Health Authority (2003) Report of an Independent Inquiry into the Care and Treatment of Daksha Emson M.B.B.S, MRCPsych, MSc and Her Daughter Freya. North East London Strategic Health Authority.

Practitioner Health Programme (2018) The Wounded Healer: Report on the First 10 Years of the Practitioner Health Service. GP Health Service (http://php.nhs.uk/wp-content/uploads/sites/26/2018/10/ PHP-report-web.pdf).

Raghuraman BS, Nataraj M, Shiva L. (2018) Psychiatry trainee stressors in a postgraduate psychiatry training centre in India. $\mathrm{Br} J$ Psychiatry Int, 16(3)

Royal College of Psychiatrists (2018) PS03/18 Supporting the Mental Health and Wellbeing of Psychiatrists. RCPsych (https://www.rcpsych. ac.uk/pdf/PSO3_18.pdf).

Taylor-East R. (2018) Working in psychiatry in Malta: a personal view. $\mathrm{Br} J$ Psychiatry Int, 16(3).

World Psychiatric Association (2017) WPA Position Statement: The Mental Health and Wellbeing of Psychiatrists. WPA (https://www. wpanet.org/uploads/Position_Statement/WPA_POSITION_ STATEMENT_ON_MENTAL_HEALTH_OF_PSYCHIATRISTS.pdf) 